Hydraulic Engineering Repository

Ein Service der Bundesanstalt für Wasserbau

Zevenbergen, Lyle W.; Lagasse, Peter F.; Clopper, Paul E.; Spitz, William J. Effects of Debris on Bridge Pier Scour

Verfügbar unter / Available at:

https://hdl.handle.net/20.500.11970/100091

Vorgeschlagene Zitierweise / Suggested citation:

Zevenbergen, Lyle W.; Lagasse, Peter F.; Clopper, Paul E.; Spitz, William J. (2006): Effects of Debris on Bridge Pier Scour. In: Verheij, H.J.; Hoffmans, Gijs J. (Hg.): Proceedings 3rd International Conference on Scour and Erosion (ICSE-3). November 1-3, 2006, Amsterdam, The Netherlands. Gouda (NL): CURNET. S. 741-749. 


\title{
Effects of Debris on Bridge Pier Scour
}

\author{
L.W. Zevenbergen*, P.F. Lagasse*, P.E. Clopper*, and W.J. Spitz* \\ *Ayres Associates Inc, 3665 JFK Parkway, Bldg. 2, Suite 200, Fort Collins, CO, USA
}

\section{INTRODUCTION}

Waterborne debris (or drift), composed primarily of tree trunks and limbs, often accumulates on bridges during flood events. Debris accumulations can obstruct, constrict, or redirect flow through bridge openings resulting in flooding, damaging loads, or increased scour at bridge foundations. The size and shape of debris accumulations vary widely, ranging from a small cluster of debris on a bridge pier to a near complete blockage of a bridge waterway opening. The effects of debris accumulation can vary from minor flow obstructions to severe flow contraction resulting in significant bridge foundation scour. Currently, there is only limited guidance available on which to base critical public safety decisions during flooding on debris-prone rivers. There is a need for accurate methods of quantifying the effects of debris on scour at bridge-pier foundations for use in the design, operation, and maintenance of highway bridges.

This paper provides a preview of the results expected from National Cooperative Highway Research Program (NCHRP) Project 24-26. The project was started in July 2004 and is scheduled for completion in December 2007. It is expected that this research project will produce results on two related problems: (1) predicting the accumulation characteristics of debris from potentially widely varying source areas, in rivers with different geomorphic characteristics, and on bridges with a variety of substructure geometries, and (2) developing improved methods for quantifying the depth and extent of scour at bridge piers considering both the accumulation variables and the range of hydraulic and geomorphic factors involved.

The project involves literature review, survey of bridge owners in the U.S., limited field reconnaissance, extensive hydraulics laboratory studies, and development of both debris accumulation guidelines and improved bridge scour prediction methods under debris loading. An early product of this research was a photographic archive of more than 700 debris accumulations on 106 streams and rivers in the U.S. This paper illustrates the scope of the problem, summarizes preliminary findings, and outlines the laboratory testing phase of the project and anticipated results.

The following specific tasks are planned to accomplish the objectives of NCHRP Project 24-26.
Phase I

Task 1 - Review The Technical Literature

Task 2 - Conduct Survey and Site Reconnaissance

Task 3 - Develop Preliminary Guidelines

Task 4 - Develop Phase II Laboratory Plan

Task 5 - Interim Report

Phase II

Task 6 - Finalize Task 3 Guidelines

Task 7 - Laboratory Studies

Task 8 - Develop Scour Prediction Methods

Task 9 - Submit Final Report

As of April 2006, Phase I was complete and preparations were being made for the initial Task 7 laboratory studies.

\section{LITERATURE SUMMARY AND SURVEY}

\section{A. Literature Review}

Both the Federal Highway Administration (FHWA) [1] and the National Cooperative Highway Research Program (NCHRP) [2] have published recent debris-related studies that have excellent reference source lists. These sources were screened and a preliminary working bibliography of the most relevant references was assembled. Then a thorough literature search of national and international literature on vegetative debris (drift) and debris impacts on bridges was completed.

This effort produced a working bibliography of 240 references. These references were screened and an annotated bibliography of the most relevant documents considering the objectives of this study were developed into a bibliography of 110 citations. Based on the annotated bibliography, a detailed literature summary was prepared to include the following topics:

- Debris source, loading, distribution, and recruitment

- Debris transport

- Debris deposition, accumulation, and storage

- Debris accumulation at bridges

- Modeling debris induced hydrodynamic forces and scour

- Managing debris accumulations at bridges 


\section{B. Survey}

Since the late 1970s there have been at least three studies related to debris that conducted surveys and/or visited state Departments of Transportation (DOTs) and other agency bridge sites. FHWA's 1979 study of "Debris Problems in the River Environment" [3] presents a literature review, a survey of debris hazards for FHWA regions and state DOTs, a debris hazard map, and a statistical analysis and observations resulting from the survey. Diehl's 1997 [1] study for FHWA compiles detailed information and maps on sources of drift (debris), Diehl also identifies debris field study sites and presents a generalized map of debris sites based on publications and written and oral communications. While Parola's [2] study for NCHRP did not include an independent survey, he relied on and interpreted the results of Diehl's [1] work; and Parola's [4] NCHRP report on "Highway Infrastructure Damage caused by the 1993 Upper Mississippi River Basin Flooding" contains specific information on debris problems and bridge failures for that region.

To supplement and update results of earlier surveys, a detailed survey to investigate regional characteristics of debris accumulations and typical bridge-related debris problems facing State DOTs was sent to 93 agencies. Surveys were returned from 88 respondents, representing 30 states including Alaska and Hawaii. In addition, two responses were returned from Puerto Rico; therefore, 84 responses representing the continental United States were received. A breakdown of responses in accordance with five geographic regions is shown in Table 1 (note that some states may be split into more than one geographic region):

\begin{tabular}{|c|c|c|}
\hline \multicolumn{3}{|c|}{ TABLE 1. } \\
\hline SURVEY RESPONSES By GEOGRAPHC REGION \\
\hline Geographic Region & Responses & States Represented \\
\hline Pacific Coast & 8 & 2 \\
\hline West & 10 & 7 \\
\hline Midwest & 29 & 11 \\
\hline South & 20 & 5 \\
\hline East & 17 & 8 \\
\hline
\end{tabular}

The survey was partitioned into seven categories. Five of the seven categories asked respondents to rank debris-related questions on a scale of 0 to 5 in terms of importance/severity of problem. Responses to all the questions in each of these five categories were examined using the Analysis of Variance (ANOVA) method to determine if statistically significant differences in the responses could be assigned to geographic regions.

In general, responses from different geographic regions tended to be similar in nature, indicating that there are relatively insignificant regional differences regarding the nature of drift accumulations at bridges.
Similarly, the types of drift-related problems reported tended to show very few regional differences. In some instances, however, regional differences were found to be statistically significant. Based on the 84 surveys received from five regions representing the continental United States, a qualitative interpretation of the survey responses combined with an analysis of variance statistics indicates the following:

- Drift material is primarily derived from unstable stream banks.

- It is most common for drift problems to occur at pile bents compared to other pier configurations. A possible exception may be in the Eastern region, where wall-type piers are reported to have the most problems.

- Large logs are not necessary for drift to begin accumulating at bridge piers. Most commonly, drift accumulation is initiated by $\operatorname{logs} 7.6 \mathrm{~m}(25$ $\mathrm{ft}$ ) or less in length, or, in the Western region, by shrubs and brushy vegetation (e.g., willows, Tamarisk).

- Nationwide, the most common drift configuration at bridges is that of an individual cluster of material on a single pier.

- Drift is most likely to exacerbate scour at bridges by either: (a) local scour at an individual pier, or (b) stream instability due to flow redirection.

- Highway departments typically do not collect cost data associated with drift removal and associated bridge repairs. Maintenance needs are sporadic in nature and are most often related to larger flood events. A reasonable range of cost estimates might be 0.5 to $1 \%$ of the DOTs total annual maintenance budget in years with little flooding, and perhaps 2 to $5 \%$ in years that experience one or more significant events.

- The relatively high standard deviation from the mean numerical responses within each region indicates that it is possible to experience the full range of drift-related problems in any given region; however, ranking the responses does provide an indication that some problems or issues are more common than others, as noted above.

\section{Debris PhotograPhIC ARChIVE}

To supplement the survey and support a regional analysis of debris accumulations, a photographic archive was compiled to assess typical debris geometry relationships. Photos of debris at bridges were acquired from a number of contributors. The photos in the archive provided the primary source used for evaluating debris accumulation characteristics and debris geometry from a wide range of sites located throughout the United States. 
The primary contributor of debris photos was Debris Free, Inc. (almost 50\% of the photos) [5]. Numerous photos were provided by state DOT personnel in response to the survey. The remaining photos were acquired from in-house sources, Internet sites, and from referenced publications. A total of 1,155 photos were acquired from the various sources. After screening and consolidation, the debris photo archive contains 736 photographs of debris-prone bridge sites on 106 rivers in all geographic regions of the United States.

\section{REgional ANALysis Of DEBRIS}

One might infer from previous studies, experience with debris problems nationally, the geomorphic characteristics of rivers in different Physiographic Regions, and the distinctly different characteristics of woody vegetation and river bank erosion processes that there should be some regional bias in debris characteristics and in debris impact on bridges. Based on the literature search, the debris photo archive, and the survey, an attempt was made to identify common (or typical) debris characteristics that might be distinguishable by major Physiographic Region or Ecoregion of the U.S.

Several studies have suggested the potential for regionalized debris generation characteristics. Reference [3] developed a depiction of a national distribution of debris problems from severe, to moderate, to minor or no problem. The distribution was based on a state-specific survey of debris problems at highway bridges nationwide and indicated that the Pacific Northwest and the upper and lower Mississippi River Valley experience the most severe debris problems. Reference [1] mapped debris sites reported by DOTs, distribution of debris field-study sites, and debris sites referenced in publications or personal communications. Diehl suggests that watersheds of high or low debris generation can be identified based on watershed characteristics such as proximity of vegetation to the stream, rate of bank erosion, and/or channel instability resulting form natural properties, climate change, fire, or human modification.

An examination of the debris characteristics and accumulation geometry from the various debris site photographs in the archive, relative to their locations on Physiographic Region and Ecoregion maps reveals that there is no identifiable or well-defined relationship with regard to the individual Physiographic Regions or Ecoregions. Instead, the typical debris accumulations can be identified and appear to be common throughout the United States, and any river or stream with a riparian corridor along its banks is susceptible to debris problems. For example, a common debris accumulation geometry was found at five different sites from various parts of the county that are in distinctly different Physiographic Regions and Ecoregions. With regard to vegetation types, only general relationships exist. In most of the eastern half of the United States, large woody debris delivered to streams and rivers is primarily from riparian forests or corridors along those streams and rivers. In the arid southwest and west, vegetation can be limited to small trees and shrub-like vegetation, and the debris accumulation sizes and geometry in these areas often reflects this type of vegetation. In the Pacific Northwest, large conifers are the dominant tree species and are the controlling factor in the size of the debris accumulations and the debris geometry in this region.

\section{DEBRis ACCUMUlation CHARACTERISTICS}

As a basis for developing a laboratory test plan, typical debris accumulation characteristics were identified from the literature review and from an examination of the photo archive. At bridges, debris characteristics at a minimum might include a single pier floating cluster, a floating raft bridging two or more piers, and submerged or sunken variations of these configurations. The debris accumulations shown in the debris photo archive database were evaluated for specific geometric characteristics and guided identification of the specific geometries described below. The photos were also used to identify typical geometries of the debris piles and provide rough estimates of debris accumulation length upstream of the pier and debris accumulation width relative to pier width.

Debris was observed accumulating at bridge piers as single logs, multiple logs, or a mass of logs. The single log accumulation was comprised of one or two logs that had become trapped on a pier or between spans. The multiple log accumulation consisted of several logs that were loosely intertwined and had no filling of the interstices or matrix with finer debris, detritus, and sediment. The mass of $\operatorname{logs}$ accumulation was composed of a cluster of logs and other debris tightly interlocked with almost all of the matrix or interstitial openings filled with smaller debris, detritus, and sediment. Unlike the mass of logs accumulation, in almost all cases, the single log and multiple log types of accumulations did not extend upstream for any significant distance. Figure 1 shows a schematic of the mass of $\operatorname{logs}$ accumulation, as well as example photos for this accumulation type.

Dongol [6] used triangular, rectangular, and elliptical planform shapes in his modeling of debris related scour. Most debris accumulations observed in the photo archive could be considered either triangular or rectangular in planform. Triangular debris accumulations tend to have a conical shape in profile, while rectangular accumulations tend to have 
a cylindrical profile. Figures 2 and 3 present schematics and photographs of the triangular and rectangular planforms, respectively. Both conical and cylindrical profile geometries were identified. Figure 4 provides a photograph of what is thought to be a debris pile with a conical geometry after the water has receded and the pile has collapsed upon itself. All types of debris accumulation profiles can evolve from being a surface accumulation to being partially or fully submerged, depending on flow depth.

A third type of profile geometry is the inverted conical profile, which generally has a triangular planform. This type of accumulation is very common and usually occurs following one or more floods when an accumulation with a triangular-conical geometry settles onto the bed of the channel. The lower portion of the accumulation then becomes embedded in the bed. This condition leads to a fourth profile, a collapsed buried wedge. When the next flood occurs, the debris accumulation remains trapped on the bed, but can grow in size because of trapping of additional debris. As more debris is trapped by the existing debris pile during subsequent flows, a rectangular-cylindrical geometry may develop.

\section{LABORATORY TEST PLAN}

A substantial laboratory testing program using the Hydraulics Laboratory of Colorado State University is planned for Phase II (Task 7). The goal of the laboratory testing will be to provide sufficient data for a range of debris accumulations to develop adjustment factors to the HEC-18 pier scour equation [7]. The adjustment factors could be a correction factor to the overall equation (such as the $\mathrm{K}_{\mathrm{w}}$ factor for wide piers) or an adjustment to the pier width used as an input variable to the equation (similar to the HEC-18 complex pier approach). The goal of the laboratory plan is to develop a series of tests for a wide range of debris configurations that can be run quickly and efficiently. Initially, the tests will be performed for single debris clusters at individual piers, which is the primary type of debris accumulation identified by all regions in the survey. These tests will then be supplemented to address specific issues related to other factors that cannot be incorporated into the initial runs. For example, other pier shapes will be tested under conditions of debris loading, including pile bents and skewed wall piers. The majority of the testing will be performed for clear-water sediment transport conditions (approach flow velocity less than the critical velocity to initiate sediment transport) for durations much less than would be required to achieve ultimate scour. The duration will, however, be sufficient to achieve at least $60 \%$ of ultimate scour. This approach to the laboratory testing will maximize the number and range of debris configurations that can be tested within the laboratory budget.

The testing will include a range of debris characteristics including debris accumulation shape, thickness, width, and length. The range of debris accumulation size that will be tested in the laboratory is related to actual debris accumulations observed in the field or from the survey sources and the photo archive. Figures 5, 6, 7, and 8 illustrate the debris shapes (rectangular, conical, collapsed inverted cone, and collapsed buried wedge) that will be modeled and define the dimensions for the various shapes. The dimensions will be varied in order to model the range of conditions typically seen in the field.

The majority of the physical modeling will be

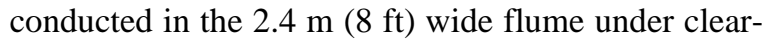
water flow conditions using $10 \mathrm{~cm}$ (4 inch) square piers. This scale and flow condition is recommended to maximize the number of debris conditions that can modeled because scour should develop rapidly at this scale and clear-water runs are also less time consuming. Table 2 shows a summary of the observed debris dimensions from the photo archive from the photo archive and the recommended range of debris dimensions for the laboratory physical modeling. All of the dimensions have been normalized by the pier width so the field conditions can be used to develop a realistic range of laboratory runs. The range of debris dimensions was selected to encompass the range observed in the field $+/$ - one standard deviation around the mean.

\section{SCOUR PREDICTION METHODS}

Based on the results of laboratory testing, methods for predicting the depth, shape, and lateral and longitudinal extent of scour at bridge piers resulting from debris accumulations will be developed. The methods will be suitable for incorporation into FHWA Hydraulic Engineering Circular 18, "Evaluating Scour at Bridges," 4th Edition [7].

For local pier scour, the concept of effective pier diameter is included in the HEC-18 complex pier scour approach. The complex pier scour approach includes the pier stem, pile cap and pile group scour amounts as independent scour components [8]. This complex pier approach is similar to the effective pier diameter approach suggested by [9]. 

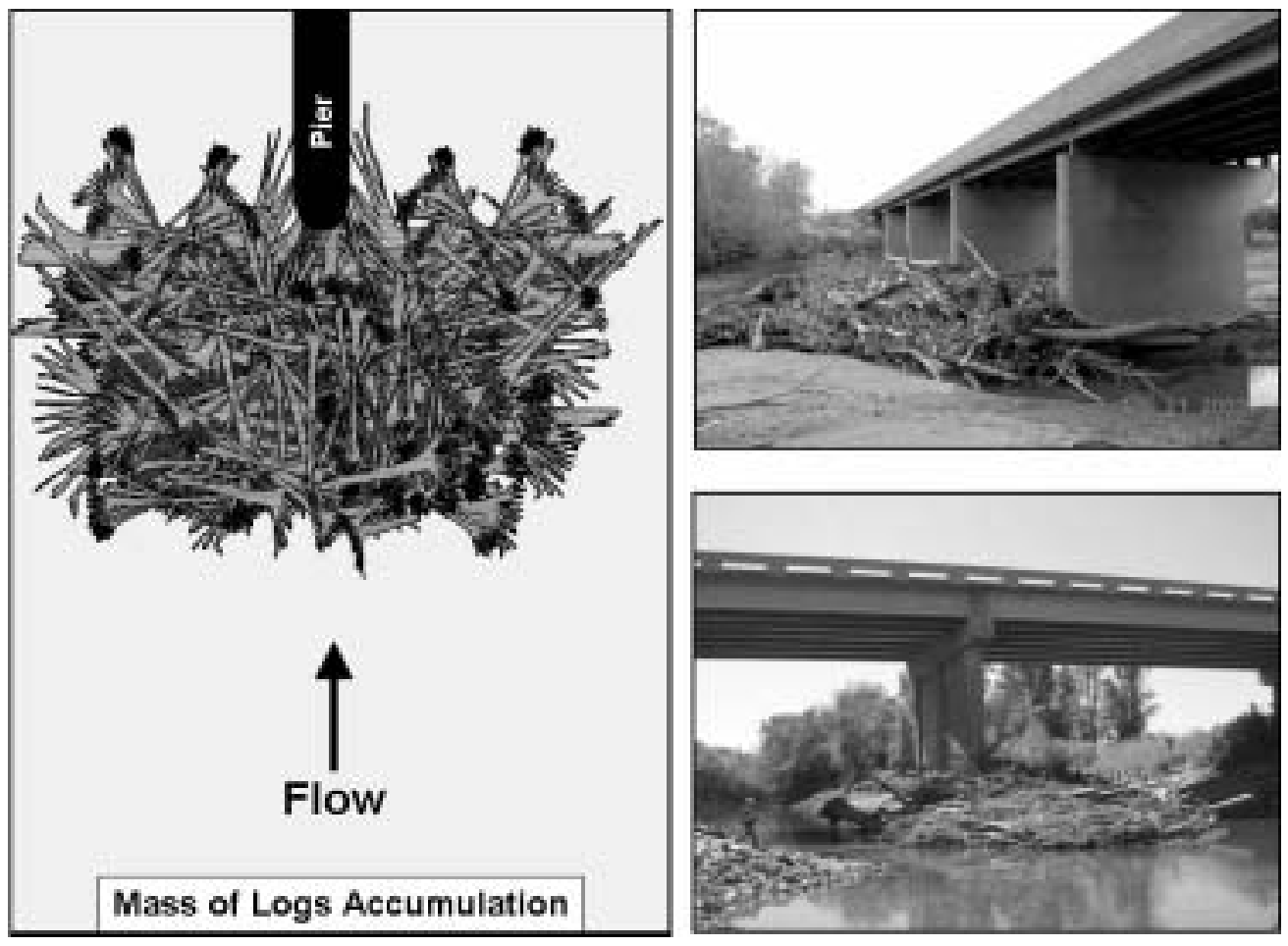

Figure 1. Mass of logs debris accumulation
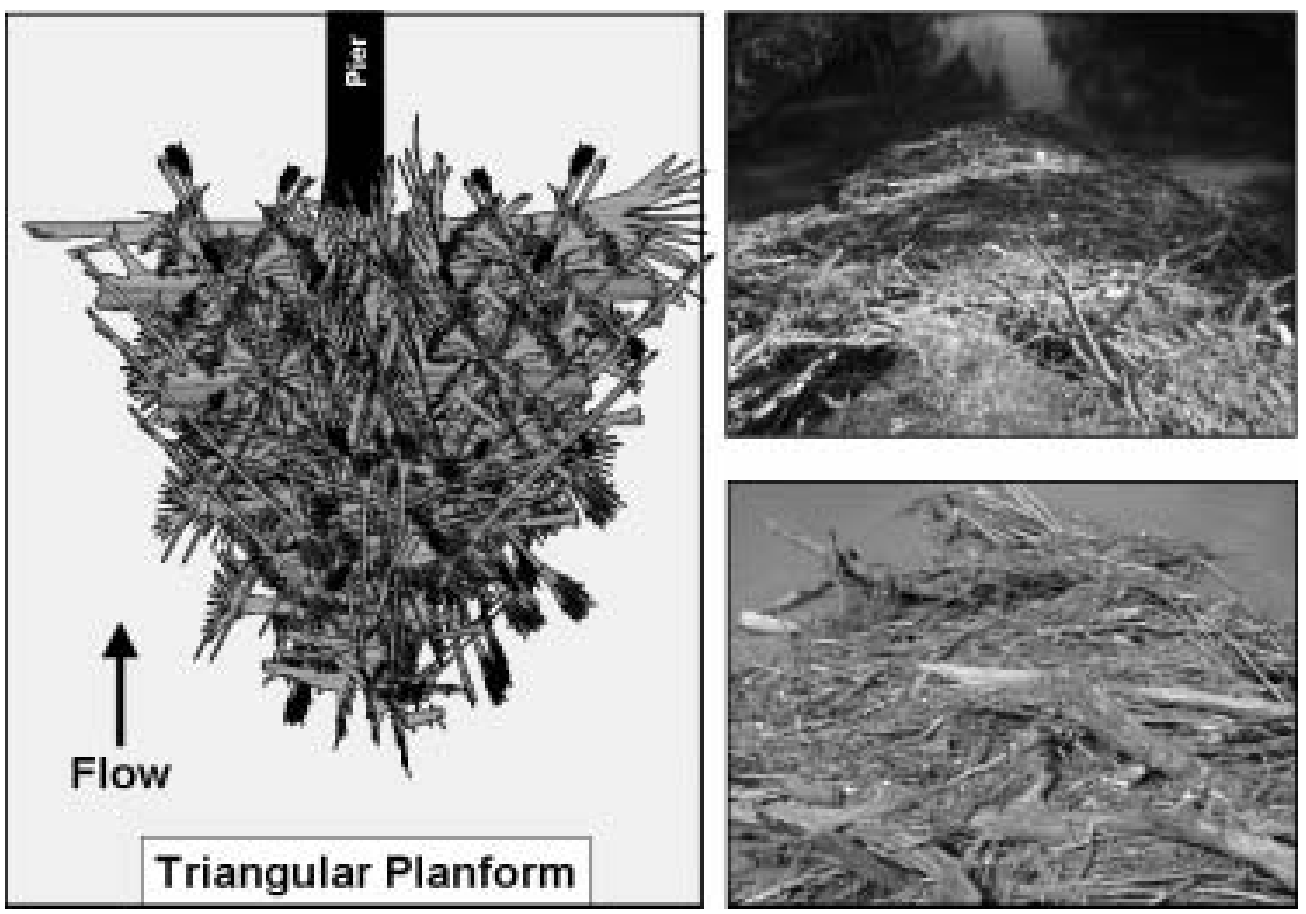

Figure 2. Triangular debris pile planform. 

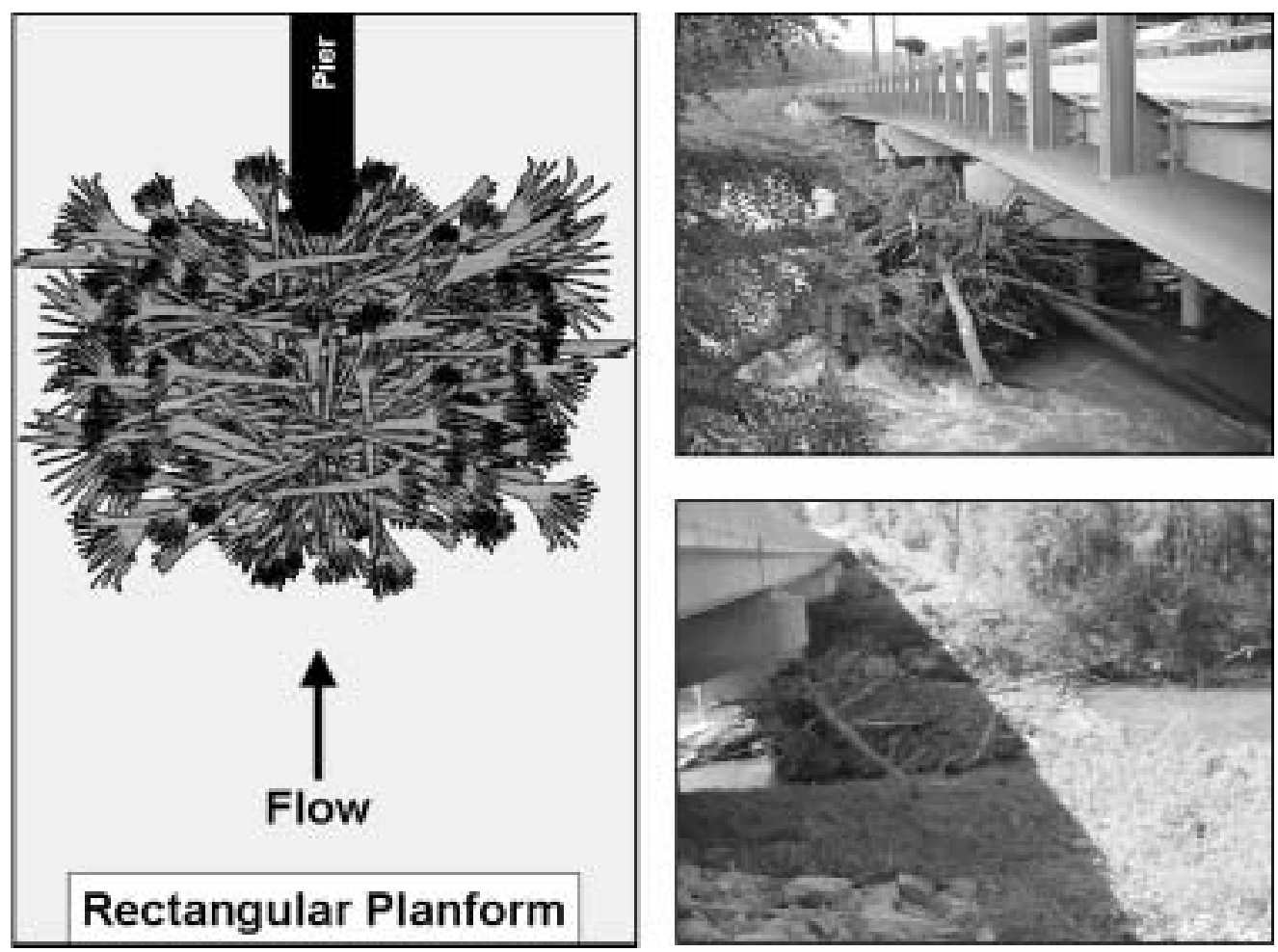

Figure 3. Rectangular debris pile planform.

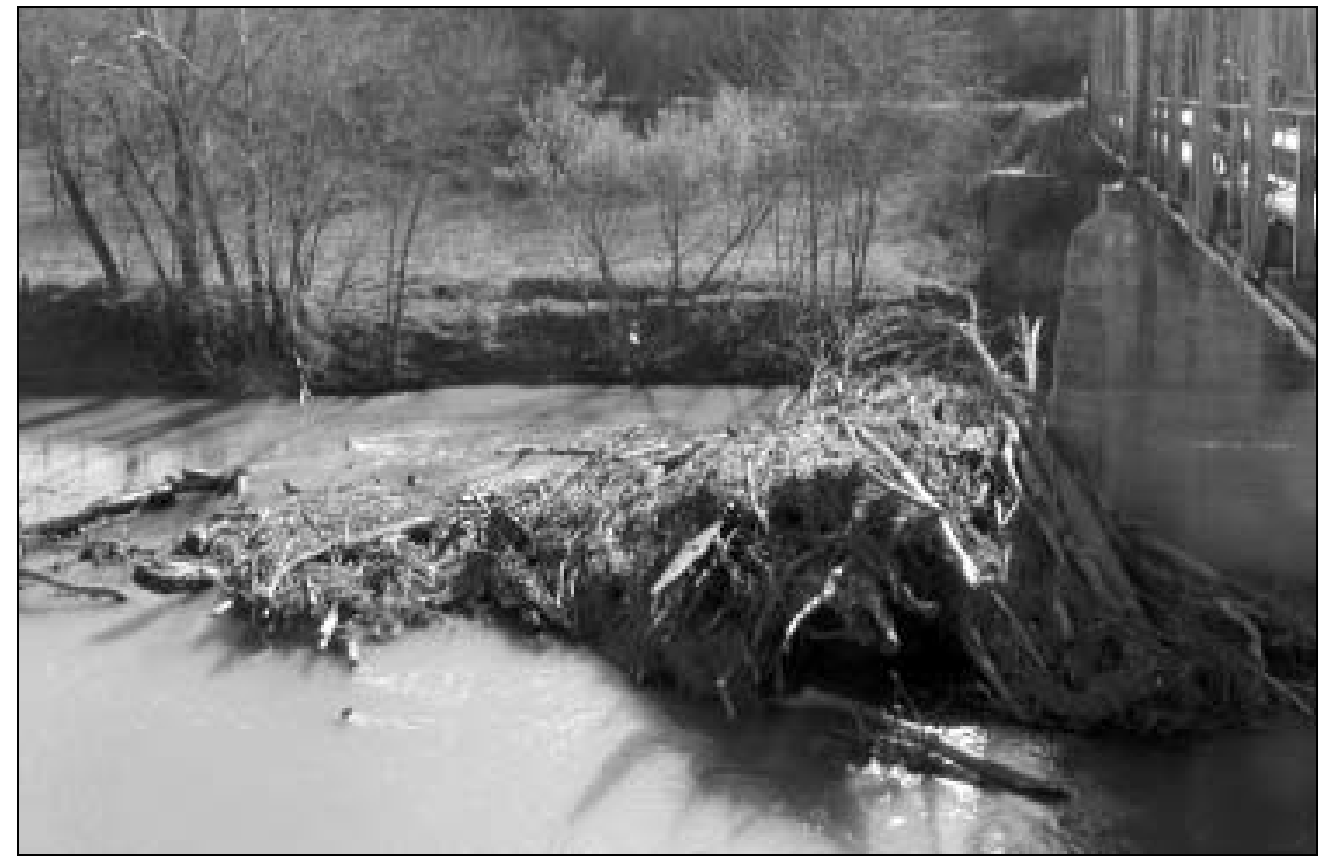

Figure 4. Debris pile with conical profile geometry. 


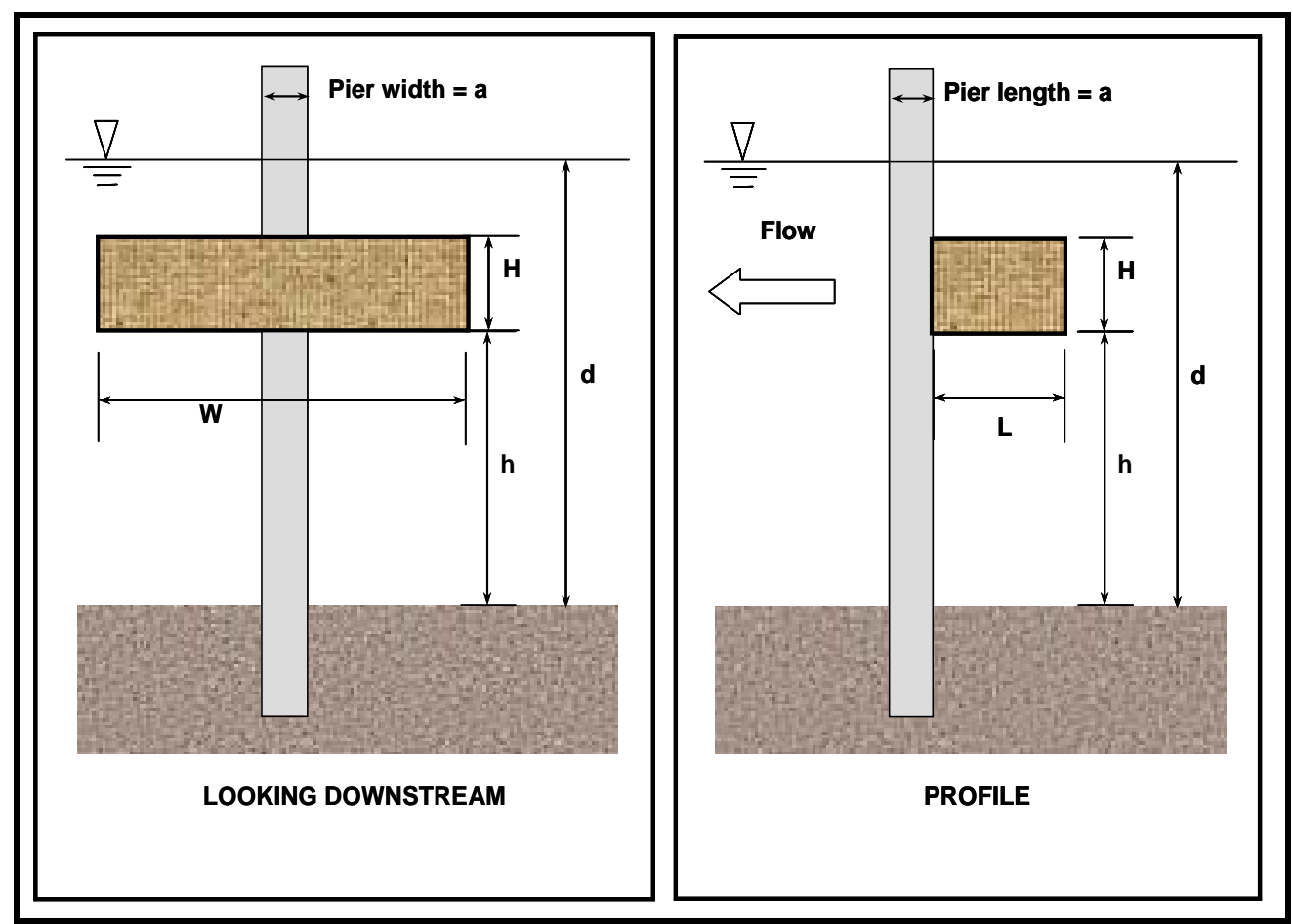

Figure 5. Rectangular shape definition sketch.

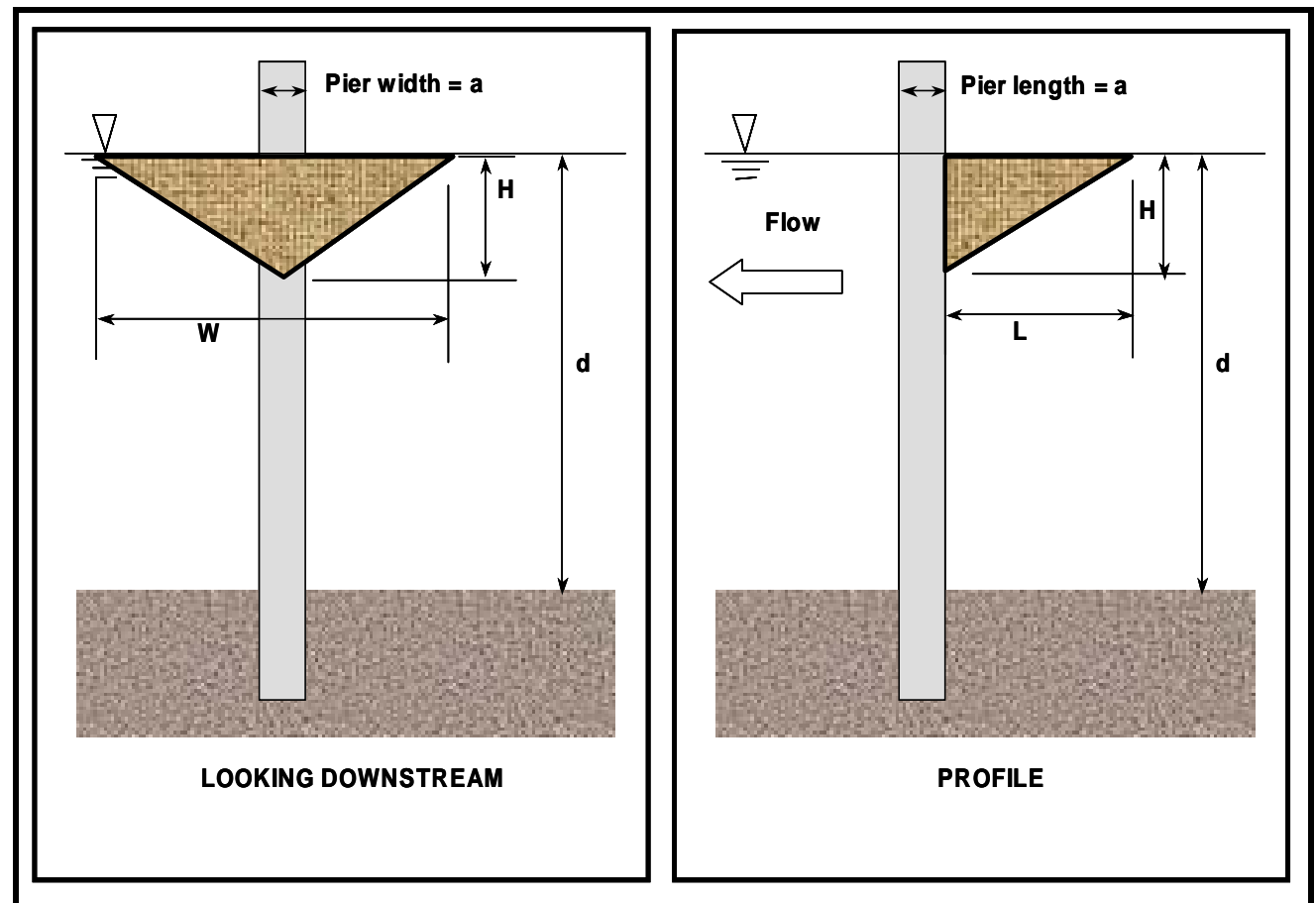

Figure 6. Conical shape definition sketch. 


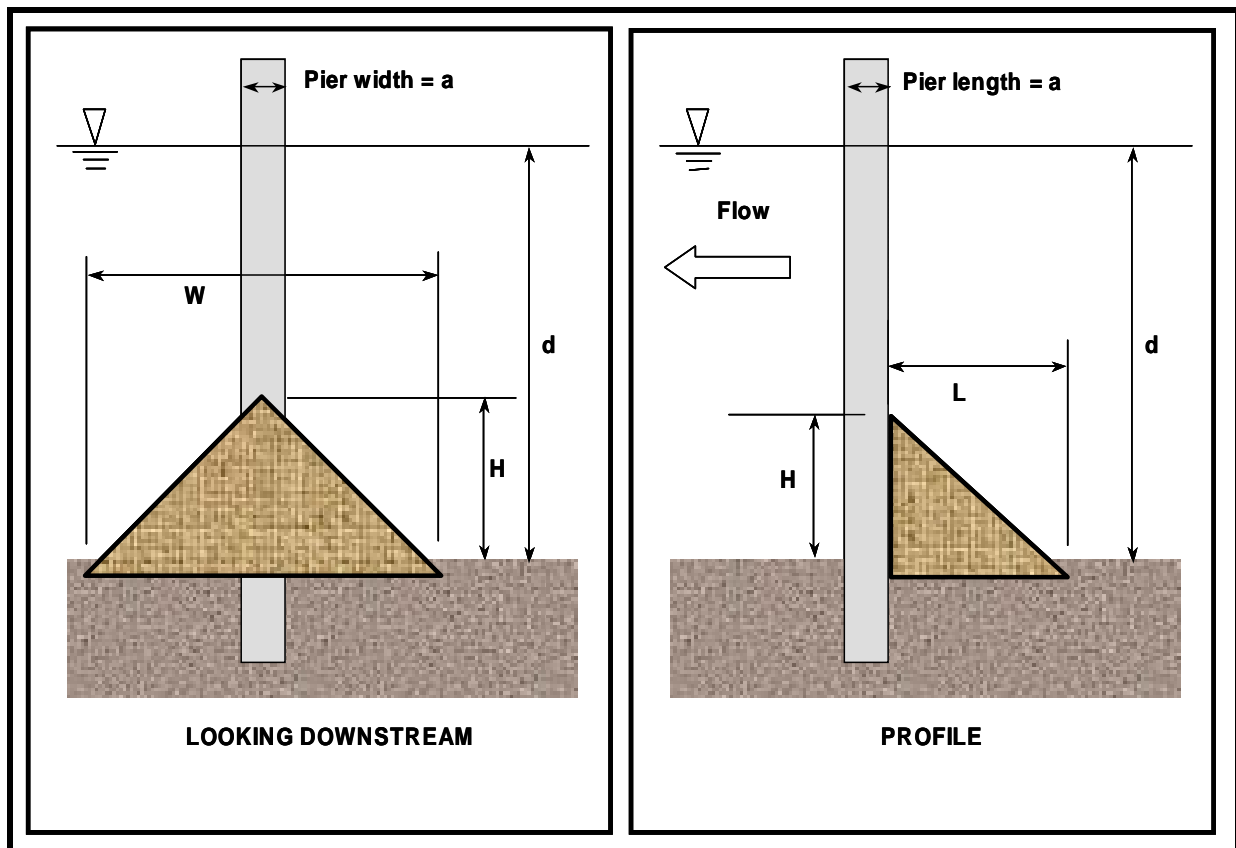

Figure 7. Collapsed inverted cone definition sketch.

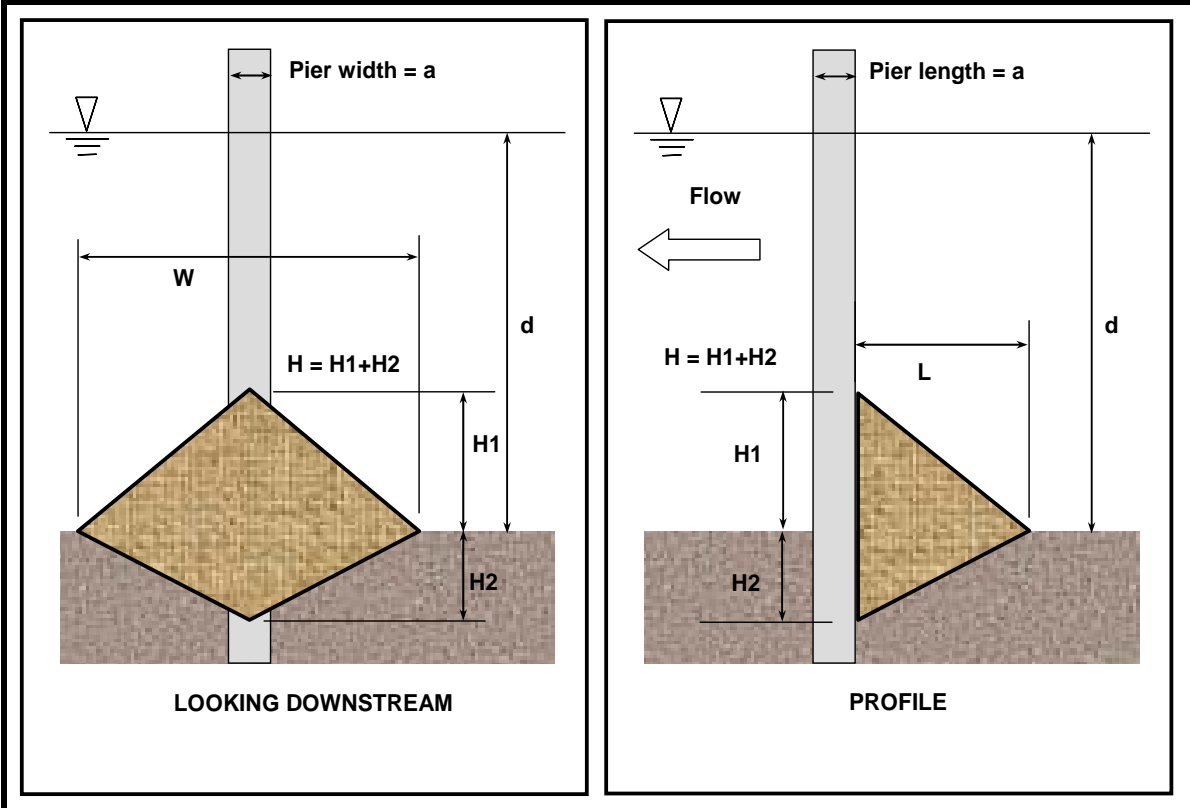

Figure 8. Collapsed buried wedge definition sketch.

\begin{tabular}{|c|c|c|c|}
\hline \multicolumn{4}{|c|}{$\begin{array}{c}\text { TABLE } 2 . \\
\text { FIELD AND LABORATORY DEBRIS DIMENSIONS }\end{array}$} \\
\hline & W/a & $\mathrm{L} / \mathrm{a}$ & $\mathrm{L} / \mathrm{W}$ \\
\hline \multicolumn{4}{|c|}{ Field and Photo Measurements } \\
\hline Average & 15.1 & 12.4 & 0.9 \\
\hline Range & $5.2-43$ & $3-48$ & $0.2-2.7$ \\
\hline St. Dev. & 8.2 & 9.2 & 0.5 \\
\hline - $/+$ St. Dev. & $6.9-23.3$ & $3.2-21.5$ & $0.4-1.3$ \\
\hline \multicolumn{4}{|c|}{ Recommended Laboratory Tests } \\
\hline Range & $6-24$ & $3-24$ & $0.5-1.5$ \\
\hline
\end{tabular}


If the effective pier diameter approach is used, the local pier scour equation in HEC-18 would remain unaltered but the effective diameter $\left(\mathrm{a}^{*}\right.$ debris $)$ would be substituted for the pier width (a). Another approach would be to add another correction factor $\left(\mathrm{K}_{\mathrm{d}}\right)$ to the local HEC-18 pier scour equation. The correction factor approach may be more easily applied but may not be as applicable to the debris condition as the effective diameter. This is because for some debris conditions the debris may totally dominate scour and the original pier diameter may have little or no contribution.

Functionally, the relationship for either $K_{d}$ or $\mathrm{a}^{*}$ debris will be related to the range of conditions tested in the laboratory. The functional relationship is:

$$
\mathrm{K}_{\mathrm{d}} \text { or } \frac{\mathrm{a}_{\text {debris }}^{*}}{\mathrm{a}}=\mathrm{fn}\left(\text { shape, } \frac{\mathrm{L}}{\mathrm{a}}, \frac{\mathrm{W}}{\mathrm{a}}, \frac{\mathrm{H}}{\mathrm{d}}, \frac{\mathrm{h}}{\mathrm{d}}, \frac{\mathrm{H}_{1}}{\mathrm{H}_{2}}, \theta\right)
$$

The dimensions a, L, W, H, h, d, $\mathrm{H}_{1}$, and $\mathrm{H}_{2}$ are shown for the various debris shapes in Figures 5 through 8 and $\theta$ is the flow angle of attack at the pier. If some of the variables or variable groupings prove to be insignificant in comparison to others, they could be eliminated from consideration.

\section{ANTICIPATED RESEARCH RESUlTS}

As a result of this research, it is anticipated that State DOTs and other bridge owners will have documentation, guidelines, and analytical procedures to quantify the effects of debris-induced scour on bridges including:

- Fully documented data base on debris and case studies, photographs, and data related to debris generation, movement, accumulation and scour at bridges that can be used to inform and train design and maintenance personnel on debrisrelated hazards.

- Necessary guidelines for predicting the size and geometry of debris accumulations at bridge piers.

- Identification of geomorphic channel types where debris delivery can be expected to be low, even during flood events.

- Methods for quantifying scour at bridge piers resulting from debris accumulations suitable for incorporation in the next edition of FHWA's HEC-18.

- Guidance for incorporating debris effects in 1and 2-dimensional hydraulic modeling.

The end result will be practical, implementable guidance for bridge owners that will enhance their ability to predict debris-related hazards at bridges and design, operate, inspect, and maintain bridges considering those hazards.

\section{ACKNOWLEDGMENT}

This work was sponsored by the American Association of State Highway and Transportation Officials, in cooperation with the Federal Highway Administration (FHWA), and was conducted through the National Cooperative Highway Research Program (NCHRP), which is administered by the Transportation Research Board (TRB) of the National Research Council (NRC).

This paper is based on an Interim Report as submitted by the authors to the TRB. The opinions and conclusions expressed or implied in the report are those of the authors. They are not necessarily those of the Transportation Research Board, the National Research Council, the Federal Highway Administration, the American Association of State Highway and Transportation Officials, or the individual states participating in the National Cooperative Highway Research Program.

\section{REFERENCES}

[1] T.H. Diehl, "Potential Drift Accumulation at Bridges," Report FHWA-RD-97-28, U.S. Department of Transportation, Federal Highway Administration Research and Development, Turner-Fairbank Highway Research Center, McLean, VA (1997).

[2] A.C. Parola, C.J. Apeldt, and M.A. Jempson, "Debris Forces on Highway Bridges," NCHRP Report 445, National Academy Press, Washington, D.C. (2000).

[3] F.F.M. Chang and H.W. Shen, "Debris Problems in the River Environment, Federal Highway Administration Report No. FHWA-RD079-62, 67 p. (1979).

[4] A.C. Parola, D.J. Hagerty, and S. Kamojjala, "Highway Infrastructure Damage Caused by the 1993 Upper Mississippi River Basin Flooding," Transportation Research Board Report 417, Washington, D.C. (1998).

[5] Debris Free Inc. Bridge Systems, http://www.debrisfree.com (2005).

[6] M.S. Dongol, "Effect of Debris Rafting on Local Scour at Bridge Piers, Report No. 473, School of Engineering, University of Auckland, Auckland, NZ (1989).

[7] E.V. Richardson and S.R. Davis, "Evaluating Scour at Bridges, Fourth Edition, Hydraulic Engineering Circular No. 18, Federal Highway Administration Publication No. FHWA NHI 01-001, Washington, D.C. (2001).

[8] J.S. Jones and D.M. Sheppard, "Local Scour at Complex Pier Geometries, Proceedings ASCE 2000 Joint Conference on Water Resources Engineering and Water Resources Planning and Management, July 3 - August 2, Minneapolis, MN (2000).

[9] B.W. Melville and D.M. Dongol, "Bridge Pier Scour with Debris Accumulation, Journal of Hydraulic Engineering, Vol. 118, No. 9, pp. 1306-1310 (1992). 